\title{
Problems of mineral raw material losses of quality and quantity management in developing of large-scale complex-structure deposits.
}

\author{
Sergei Tkach $^{1 *}$ \\ ${ }^{1}$ Mining Institute of the North, Siberian Branch, Russian Academy of Sciences, Yakutsk, Russia
}

\begin{abstract}
The article deals with the problems of mineral raw material losses of quality and quantity management in developing of large-scale complex-structure and composition deposits of solid minerals. It is shown that a very high degree of mining and geological conditions variability in time and space for the development of mining units is typical for such deposits. This significantly complicates the qualitative and quantitative operating losses setting and accounting of mineral raw materials during its extraction in the framework of existing general and industry regulatory documents. Conceptual principles for face-by-face operational setting of losses and impoverishment of minerals for the conditions of bulk mining of complex-structure deposits with the formation of gross mining flow with economically feasible and specified level of quality (the content of commercial and harmful components) are stated. These principles generally do not contradict effective instructions main provisions and are made to minimize the total operating losses during the processing of several mine sections (faces). Key words: mining and geological conditions, mining unit, losses, impoverishment, mining flow, setting, efficiency.
\end{abstract}

\section{Introduction}

From the point of view of an economically feasible and environmentally acceptable level of mineral raw material qualitative and quantitative losses, the problems related to planning and organizing mining operations are exacerbated during the exploitation of large-scale complex-structure deposits of solid minerals.

Extremely high diversity and variability of the internal (natural, mining and geological and other operational conditions) and external (market conditions, variability of prices for goods, services, etc.) environment [1, 2, etc.] - main reason for problems exacerbation. It is necessary to simultaneously use the various technologies, development systems and their elements during such deposits exploitation. This significantly complicates the setting and accounting for the solid minerals qualitative and quantitative losses.

Without dwelling on influence of the external environment variability on impoverishment and losses standard ratios technical-economic justification and efficiency of the mining enterprise as a whole, let's look at the effect of mining and geological conditions aggregate of field operation, in particular, the process of normalization of operational qualitative and quantitative losses of minerals on open-cast mines.

\footnotetext{
*Corresponding author: tkach@igds.ysn.ru
} 


\section{Materials and techniques}

The whole aggregate of mining and geological conditions (the thickness of productive bodies, dip angles and extent, useful and harmful components content, adjacent-and-oresformation stability and strength, high-amplitude geological disturbances, etc.) also changes as each extraction ledge (face) moves. The situation is aggravated by the high variability, inadequate texture and detection accuracy in the process of detailed exploration and advanced in-mine sampling of the geological environment main factors [1-5, etc.]. There is no doubt that the authors' assertion ([6], p. 8) that ... "technological standards for quantitative production losses established for each extraction unit (EU) can and should be the basis for assessing the economic efficiency of the extraction completeness of minerals from subsoil". According to subsoil protection rules (Order of the Ministry of Natural Resources of the Russian Federation of March 28, 2012 No. 257), the extraction unit, which accounts for the state and movement of reserves, losses and impoverishment of minerals, is defined as the minimum section of the field having relatively homogeneous geological conditions. Its mining within the framework of the adopted design solutions is carried out by one mining system, a technological scheme of extraction (quarry, ledge, block, lava, chamber, accumulation, deposit, etc.). Within the EU, the reserves are determined with sufficient reliability and a reliable primary accounting for minerals and components extraction (mining) is possible. Due to the extreme variability in time and space of the conditions for large complex-structure deposit mining it would be not possible to justify and identify EU with homogeneous geological conditions for their mining in a certain period of time (year, quarter, and month) even within a single ledge or block.

It is also true [6] that, despite the transition from the planned economy to the market economy of the country in the 90 s of the last century, so far they have retained their legitimacy, practical significance and widespread applicability "Standard methodological regulations ..." (SMR) [7]. It should be emphasized that the main SMR and other applicable industry normative documents provisions [8, etc.] do not exhaust the existing opportunities to reduce raw-materials losses in near-contact zones where the formation of the mining flow of large-scale complex-structure deposits is performed by aggregate of faces that different from each other at mining and geological and mine technical conditions of their treatment. Among such conditions: the angle of accumulation dip; ore, coal and wallrock hardness; the content of useful components in the ore or the ash content of coal wallrock; orientation of the near-contact zones on the direction of face movement; gradient of slope and the height of the developed ledge; width of the bench.

It is known that when face flows merge with each other, qualitative ratios averaging takes place in a united mining flow. Along with this, the functions of losses quantities interrelation with impoverishment quantities are also averaged. The nature of these functions is determined by the changing development conditions in faces of the nearcontact zones containing mineral resources with the wall rock. This also has a direct effect on the quality of the total mining flow - the content of useful or harmful components. This circumstance makes it very difficult, and in most cases makes it impossible to single out and justify the EU characteristics, which according to the methodological principles of SMR does not allow economically and reasonably to standardize the level of qualitative and quantitative raw materials losses during the development of the near-contact zones.

\section{Results and discussion}

Face-by-face operational setting of losses and impoverishment of minerals conceptual principles for the conditions of gross development of complex-structure deposits in the formation of a common mining flow of economically justified and regulated quality (useful 
and harmful component content) are described in [9]. They generally do not contradict to the basic SMR provisions and are aimed to minimize the total operational losses during development of several mine sections (faces). These principles of face-by-face setting are based on a mathematical interpretation of functions of losses quantities interrelation with impoverishment quantities, expressed in terms of the thickness of their layer referred to length unit of the technological surface formed during the development of the appropriate near-contact zone, and their relationship with the values of the bulk mining controlled technological parameters $\mathrm{h}_{1}, \mathrm{~h}_{\mathrm{i}}, \Delta \mathrm{h}, \mathrm{Z}, \mathrm{K}_{\mathrm{l}}, \Delta \mathrm{W}$ (Fig.1). Values of these technological parameters allow to carry out geological survey control and extraction quality level control procedures in the mining process, taking into account the fulfillment of the following conditions:

$$
P_{o}, A_{o}, a_{o}=\text { const } ; L_{o} \rightarrow \min ,
$$

$L_{o}$ - total losses of useful mineral resources during working out of extraction blocks (faces), $\% ; \mathrm{P}_{\mathrm{o}}$ - total impoverishment share, $\% ; \mathrm{A}_{\mathrm{o}}$ - harmful components content, $\% ; \mathrm{a}_{\mathrm{o}}$ useful components content, $\%$.

The optimization calculation method of the total losses minimum in the regulated quality of the mining flow $\left(\mathrm{P}_{0}, \mathrm{~A}_{0} \mathrm{a}_{0}\right)$, formed by several extraction units, is based on the use of a well-known method for solving such problems based on the Lagrange optimization function formation.

For the above method, based on the initial data close to the real ones, modeling was performed. Calculations show that the difference of the total losses calculated by the SMR and the present method is very significant in all considered options of the cumulative development of extraction blocks with the regulated impoverishment of the $\mathrm{P}_{\mathrm{o}}$ mining flow formed by $\mathrm{N}$ faces, with differing mining and geological conditions for their development. In absolute calculus, depending on the of $\mathrm{P}_{\mathrm{o}}$ value and the specific conditions of the faces, their difference varies from tenths of a percent to several percent $(0.1-5 \%)$, in relative terms - from several percent to tens of percent (2-30\%). Approximately the same ratios are very likely with the regulated quality of the total mining flow formed by $\mathrm{N}$ faces - harmful $\mathrm{A}_{O}$ content (ash content) and $\mathrm{a}_{\mathrm{o}}$ useful components.

A

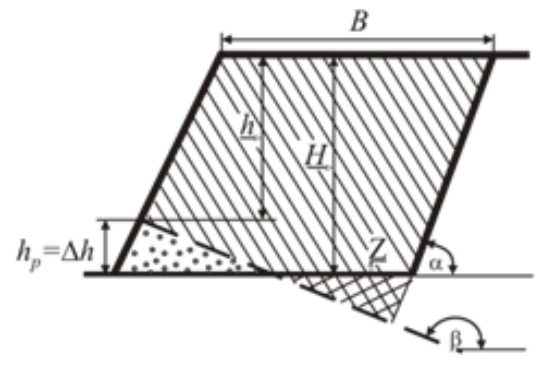

B

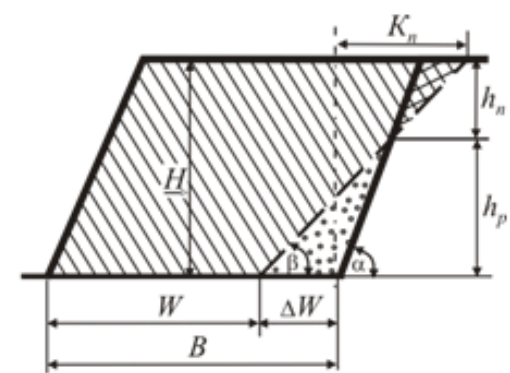

\section{MIIIV- Mineral Resource}

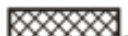

Losses

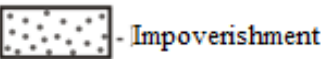

Fig. 1. Scheme for calculating the interrelation between qualitative and quantitative losses including technological parameters of bulk mining: A - inclined accumulation (deposits); B - steep fall accumulations (deposits)

The algorithms of face-by-face optimization of the loss and impoverishment values described in [9] for the regulated quality of the total mining flow in the bulk mining of complex-structure deposits in accordance with the SMR can also be used as an auxiliary tool for setting by the criterion "maximum profit per 1 ton of deplited deposits. Modeling the optimization calculations for the variables $\mathrm{P}_{0}, \mathrm{~A}_{\mathrm{o}}$ or $\mathrm{a}_{0}$, we obtain some matrices of the values of the minimum possible total losses and the corresponding impoverishment. 
Knowing the ratio of the losses and impoverishment total values, a variant of the minimum possible level of total losses of minerals is determined through the appropriate technical and economic calculations. In addition, it is also possible to optimize (in terms of completeness and quality of extraction) the values of technological parameters that included in the optimization functions: $\mathrm{q}$ - bottom-hole (face) productivity, $\mathrm{m}^{3} /$ unit. time; $\mathrm{H}$ - height of the mining ledge (bench), m; B - bench width of the face-to-face sloughing, m; $\alpha$ is the slope angle of the mining ledge, deg.

In [10], the question of determining the optimal height of the mining ledge, taking into account the level of losses for the quarries of "ALROSA", PJSC diamond mining company, was considered. The task of optimizing the height of the mining ledge implies its influence on the damage from loss and impoverishment, with attribution of 1 ton of extracted ore mass. However, in this case, the fact of formation of a common mining flow from several faces and the interdependence of this with the achievement of the goal to minimize the losses of minerals, other things being equal, is not taken into account. The latter approval is also very typical for the requirements (recommendations) of the current regulatory documents on the setting of losses and impoverishment during mining of mineral raw materials.

\section{Conclusions}

At mining enterprises in modern conditions, in the planning of mining operations and in the management of production processes, during the process of operation digital 3D models of the developed objects are being widely used, constantly replenished and refined, which greatly facilitates and accelerates the very laborious planning and normalization process.

In addition to normalizing the values of losses and impoverishment of mineral resources in the development of near-contact (near-boundary) zones of deposits, from the point of view of management of losses in the quality of mineral raw materials during mining, an important problem is the process of planning the organization of mining operations, taking into account the inhomogeneity of the mineral raw materials harmful and useful components spacing. It is very typical for large complex-structure deposits $[1-5,11$, etc.]. Mining and geological conditions high variability and the variability of the content of harmful and useful components of mineral raw materials from large-scale complexstructure deposits presupposes the need to develop for each of them a special system for integrated management of the quality of extracted raw materials. Moreover, in addition to achieving the goal of averaging quality (stabilization), it should be synchronized as much as possible with the process of setting, recording and economic evaluation of losses of solid mineral resources during their extraction. The use of the above-mentioned principles of normalizing operating losses and impoverishment in the aggregate of mining faces in the realization mode of differentiated fields in the field and dynamic operational conditions mode, that operatively take into account the specifics of the conditions for working out specific extraction units will be used in operating quarries and mines to improve the completeness of extracting stocks from the subsoil.

\section{References}

1. S. M. Tkach, Methodological and geo technological aspects of increasing of efficiency of mastering of ore and Yakutian placer deposits). Responsible editor: S.A. Batugin; Institute of Mining of the North, the Siberian Division of Russian Academy of Sciences, Yakutsk: Publishing House of Geocryology Institute. p. 284. (2006). 
2. S.M. Tkach. Mining Informational and Analytical Bulletin, Problems of integrated development of geo-resources: special issue. 21. pp. 522-536. (2016).

3. Villaescusa E. Geotechnical Design for Sublevel Open Stoping. CRC Press. 541 p. (2014).

4. Matthews T. Impoverishment and ore loss projections: Strategies and considerations / 2015 SME Annual Conference and Expo and CMA 117th National Western Mining Conference. Mining : Navigating the Global Waters; Denver; United States. pp. 529-532. (2015).

5. Parker H.M. Mining Techn. : Institute of Materials, Minerals and Metallurgy and the ausimm. 121 (3). pp. 160-176. (2012).

6. K. N. Trubetskoi, E. I. Panfilov. Mine survey and subsoil use. 4. pp. 3-13. (2015).

7. Typical methodological regulations for the definition, setting, accounting and economic valuation of losses of solid minerals in their extraction (Copy and cartographic enterprises of the All-Union Geological Fund). pp. 224. (1972).

8. Methodological guidelines for the setting, identification and accounting of losses and impoverishment of gold-bearing ore (sands) during mining (Irgiredmet, pp. 265). (1994).

9. S. M. Tkach, Block normalization of losses of minerals with the regulated quality of the miming: Recommendations (Yakutsk Scientific Center, Siberian Division, Russian academy of Sciences). (1992).

10. S. S. Mining, A. N. Akishev, Determination of the optimal height of the mining ledge taking into account the level of losses for deposit quarries "ALROSA", PJSC, Diamond mining company // Mine survey and subsoil use. 6. pp. 52-55. (2014).

11. E. A. Khoiutanov, V. L. Gavrilov, Management of ash content of complex-structure layer in open mining operations // Mining informational and analytical bulletin, spec. 21. pp. 163-171 (2016). 